\title{
Saline infusion sonography compared to hysteroscopy for uterine cavity evaluation in abnormal uterine bleeding
}

\author{
Gabriela Dimitriu', Ibrahim A. Abdelazim²,3, Shikanova Svetlana4, Gulmira Zhurabekova ${ }^{5}$, \\ Rami S. Alrbeihat ${ }^{6}, 0$ mar A. Taso ${ }^{6}$ \\ 'Department of Obstetrics and Gynaecology, South Tyneside Hospital, UK \\ 2Department of Obstetrics and Gynaecology, Ain Shams University, Cairo, Egypt \\ ${ }^{3}$ Ahmadi Hospital, KOC, Ahmadi, Kuwait \\ ${ }^{4}$ Department of Obstetrics and Gynaecology, Marat Ospanov, West Kazakhstan State Medical University, Aktobe, Kazakhstan \\ (WKSMU) \\ ${ }^{5}$ Department of Normal and Topographical Anatomy, Marat Ospanov, West Kazakhstan State Medical University, Aktobe, \\ Kazakhstan (WKSMU) \\ ${ }^{6}$ Department of Obstetrics and Gynaecology, King Hussein Medical Centre (KHMC), Amman, Jordon
}

\begin{abstract}
Introduction: Evaluation of abnormal uterine bleeding (AUB) in women $\geq 40$ years or menopausal women is of critical importance to confirm the benign nature of the problem, and to exclude endometrial carcinoma. This study was designed to evaluate the accuracy of saline infusion sonography (SIS) compared to hysteroscopy in diagnosing uterine cavity abnormalities in cases of AUB.

Material and methods: One hundred and eighty-six women diagnosed with AUB were included in this comparative study, and agreed to have SIS, beside the hysteroscopic assessment of the uterine cavity.

Results: In this study, hysteroscopy was more sensitive (98.7\% vs. 97.4\%), more specific (100\% vs. 99.1\%), and more accurate (99.5\% vs. $98.4 \%$ ) than SIS. In addition, hysteroscopy had higher predictive values, $100 \%$ positive predictive value, and $99.1 \%$ negative predictive value compared to $98.7 \%$ positive predictive value, and $98.2 \%$ negative predictive value for SIS in diagnosis of uterine cavity abnormalities. However, these differences were not statistically significant $(p>0.05)$.

Conclusions: Saline infusion sonography is a simple, well-tolerated procedure that can be used in an outpatient setting to diagnose uterine cavity anomalies in cases of abnormal uterine bleeding when outpatient hysteroscopy is not available or as a complementary tool to confirm the diagnosis detected by hysteroscopy.

Key words: saline, sonography, hysteroscopy, uterine, bleeding.
\end{abstract}

Corresponding author: Prof. Ibrahim A. Abdelazim, Ahmadi Kuwait Oil (KOC) Company Hospital, P.O. Box: 9758, 61008 Ahmadi, Kuwait, phone: +965-66551300, e-mail: dr.ibrahimanwar@gmail.com 


\section{Introduction}

Abnormal uterine bleeding ( $\mathrm{ABU})$ is a major problem in gynaecology, constituting $33 \%$ of outpatient referrals, and $69 \%$ of peri-menopausal and postmenopausal women referrals $[1,2]$.

Evaluation of abnormal uterine bleeding in women $\geq 40$ years or menopausal women is of critical importance to confirm the benign nature of the problem, and to exclude endometrial carcinoma, so that medical or conservative treatment can be offered, and unnecessary surgery can be avoided $[2,3]$.

Uterine cavity evaluation is a basic step in the investigation of abnormal uterine bleeding [4]. Hysteroscopy is known as the gold standard procedure for uterine cavity assessment. It enables diagnosis, and treatment of intrauterine pathology in the same outpatient setting [5].

Hysteroscopy is an excellent tool for the diagnostic and therapeutic work-up in women with abnormal uterine bleeding [5-7].

Trans-vaginal ultrasonography (TVS) is the standard method applied to screen for possible endometrium or uterine cavity abnormalities [8].

The uterus can be expanded with saline during TVS in saline infusion sonography (SIS), or in saline infusion hysterosalpingography (SIHS) [5]. It has been reported that the expansion of the uterine cavity with saline during trans-vaginal sonography improves the delineation of uterine cavity abnormalities [9-12].

This study was designed to evaluate the diagnostic accuracy of SIS compared to diagnostic hysteroscopy in diagnosing uterine cavity abnormalities in abnormal uterine bleeding.

\section{Material and methods}

One hundred and eighty-six women with abnormal uterine bleeding were randomly enrolled in this comparative study conducted over 2 years from January 2011 to January 2013.

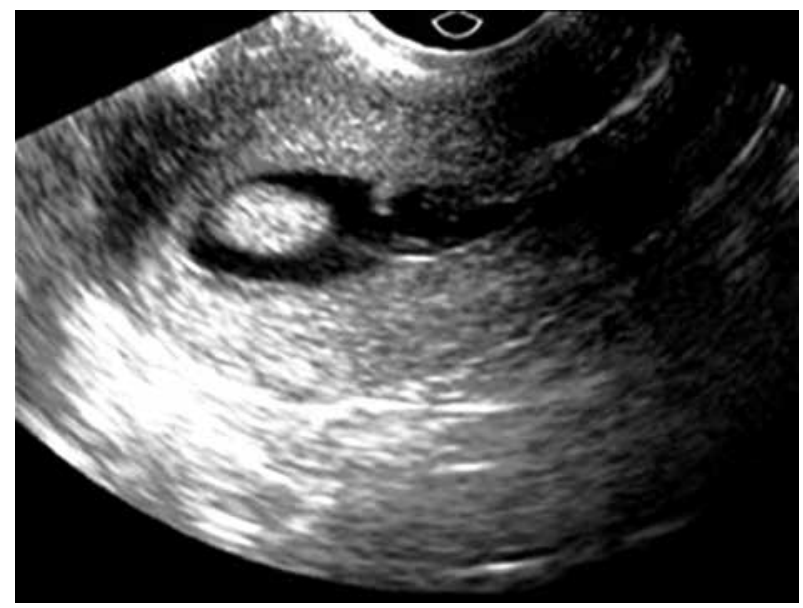

Figure 1. Saline infusion sonography diagnosis of endometrial polyp
Ethical approval of the study was given by the local institute ethical committee of Ahmadi Hospital, Kuwait Oil Company (KOC), Ahmadi, Kuwait. After informed consent, we performed a detailed clinical assessment of the participants followed by laboratory investigations (complete blood count (CBC), coagulation profile, prolactin, thyroid and liver function tests).

Inclusion criteria were women $\geq 40$ years presenting with abnormal uterine bleeding, endometrial thickness $>4 \mathrm{~mm}$, normal activated partial thromboplastin time (APTT), and normal platelet count.

We excluded women with possibility of pregnancy, history of contraception, who received hormonal treatment in the last 6 months before inclusion in this study, endometrial thickness $\leq 4 \mathrm{~mm}$, women with endocrine disorders, and abnormal liver function tests.

Participants agreed to have a trans-vaginal ultrasound assessment of the uterine cavity using saline as the contrast medium (SIS) beside the hysteroscopic assessment.

Both hysteroscopy and SIS procedures were done postmenstrually in the early-mid follicular phase of a cycle of the same menstrual cycle.

Trans-vaginal ultrasound was done by an expert sonographer, blinded to the patients' data, using a Philips HD9 (Philips Inc., Amsterdam, Netherlands) with 2D convex probe 4-9 MHz.

We initially examined the myometrium, and endometrium in longitudinal and transverse planes. Irregularities and any distortion of the endometrial echo were noted. Thereafter we inserted a paediatric Foley catheter (No. 5) through the cervix and inflated it with $1-2 \mathrm{ml}$ of saline for self-retention. Five to fifteen (5-15) $\mathrm{ml}$ of physiologic saline solution was slowly infused to distend the uterine cavity during continuous scanning (Figure 1).

The uterus was evaluated regarding its contour, dimensions, thickness of the endometrium, and presence of polyps or fibroids during the distension and at the end of it.

Hysteroscopies were done in a standardized manner, using a $4-\mathrm{mm}$ diameter Bettocchi hysteroscope with a $30^{\circ}$ field of view (Karl Storz Endoscopy, Utrecht, Netherlands).

Normal sterile, isotonic saline solution was used for distension of the uterine cavity. The uterine cavity was assessed as regards its shape (normal, arcuate or septate), and the presence or absence of abnormalities (endometrial polyps, myomas, adhesions and septa).

Any uterine abnormalities diagnosed in the studied cases were treated using operative hysteroscopy under general anaesthesia, and specimens obtained were sent for histopathological examination.

Participants received a non-steroidal analgesic $30 \mathrm{~min}$ before the SIS and hysteroscopy, and prophylactic antibiotics (200 mg of doxycycline before followed by $100 \mathrm{mg}$ twice daily for 10 days after). The diagnosis of endometrial polyps, endometrial hyperplasia and atrophic endometrium was confirmed when the result of histopathological examination of the endometrial biopsies taken during hysteroscopy was obtained, while the diagnosis of sub-mucous myoma and intrauterine adhesions was confirmed when the recorded 
findings during hysteroscopy were reviewed by a senior gynaecologist [5].

\section{Sample size}

The required sample size was calculated using G Power software version 3.17 for sample size calculation (Heinrich Heine Universität; Düsseldorf; Germany), setting $\alpha$-error probability at 0.05 , power $(1-\beta$ error probability) at $0.95 \%$ and effective sample size $(\mathrm{w})$ at 0.3 . The effective sample includes more than 110 women needed to produce a statistically acceptable figure.

\section{Statistical analysis}

Statistical analysis done using Statistical Package for Social Sciences version 20 (SPSS 20), (Chicago, IL, USA). Data are presented as number $(n)$ and percentage (\%), and the chi-square test $\left(\chi^{2}\right)$ was used for statistical analysis. The significance level was set at 0.05 .

Sensitivity is the proportional detection of individuals with the disease of interest in the population. Specificity is the proportional detection of individuals without the disease of interest in the population. Positive predictive value (PPV) is the proportion of all individuals with positive tests, who have the disease. Negative predictive value (NPV) is the proportion of all individuals with negative tests who are non-diseased.

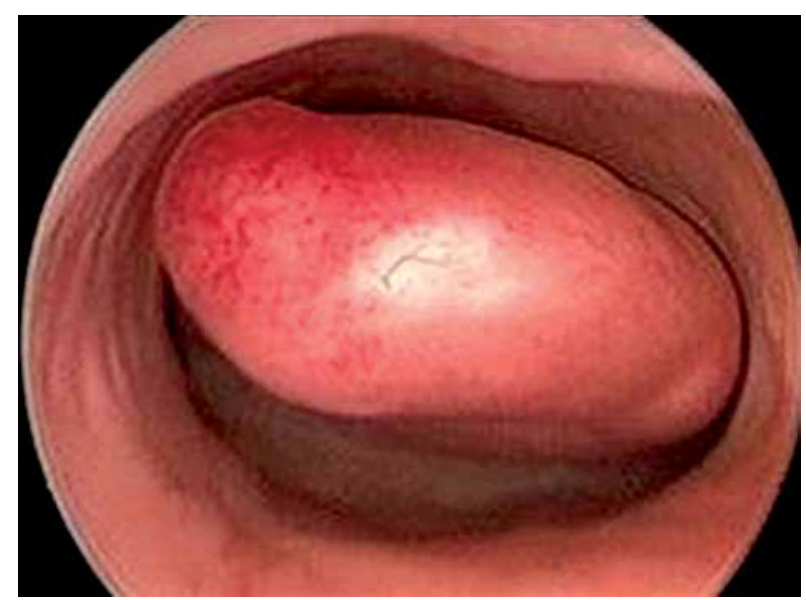

Figure 2. Hysteroscopic diagnosis of endometrial polyp

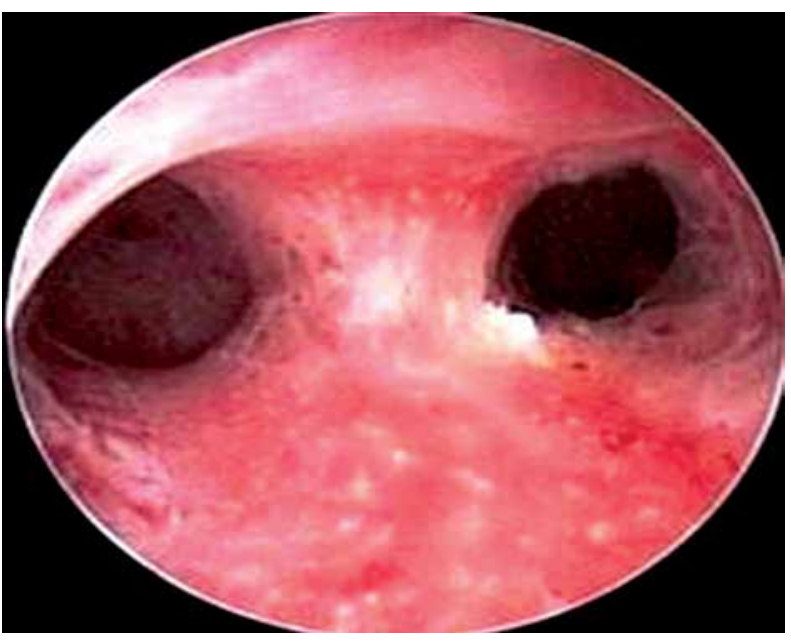

Figure 4. Hysteroscopic diagnosis of uterine septum

\section{Results}

One hundred and ninety women were included at the beginning of this study to compare the accuracy of SIS to hysteroscopy in diagnosis of uterine cavity abnormalities in women presenting with abnormal uterine bleeding. Two records and two histopathology reports were lost during patients' follow-up and finally statistical analysis done for 186 women.

Uterine cavity abnormalities were diagnosed in $40.3 \%$ $(75 / 186)$ of the women included in this study $(17.7 \%$ (33/186) endometrial polyps (Figure 2), 10.2\% (19/186) sub-mucous fibroid (Figure 3), 4.8\% (9/186) uterine septum (Figure 4), 3.2\% (6/186) uterine adhesions (Figure 5), 2.8\% $(5 / 186)$ endometrial hyperplasia, and $1.6 \%(3 / 186)$ thin or atrophic endometrium) (Table 1).

During hysteroscopic evaluation of the uterine cavity of the studied cases, one case of small sub-mucous fibroid was diagnosed as normal uterine cavity (one case false negative), while during SIS evaluation of the uterine cavity of the studied cases, two cases were diagnosed as normal uterine cavity (one case of endometrial polyp + one case of Asherman's syndrome (two cases false negative)), and one case of endometrial polyp was diagnosed as endometrial hyperplasia (one case false positive) (Table 1).

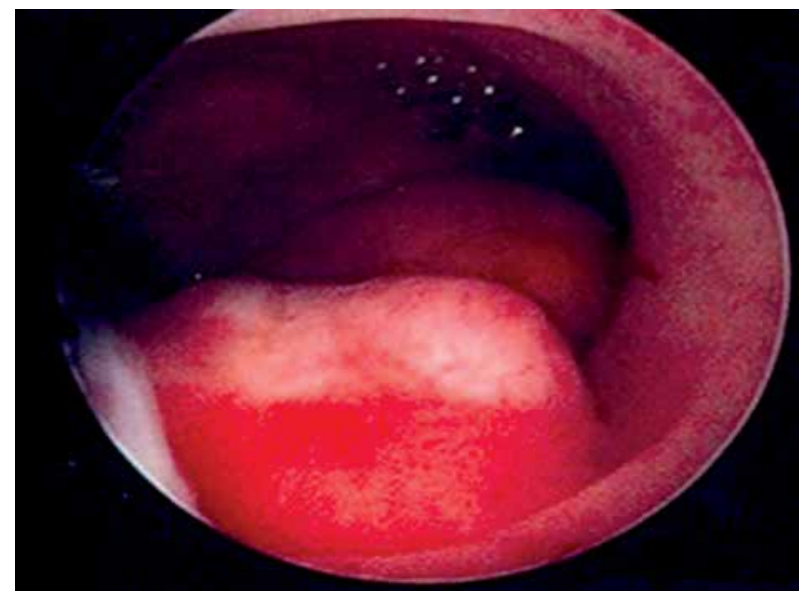

Figure 3. Hysteroscopic diagnosis of sub-mucous fibroid

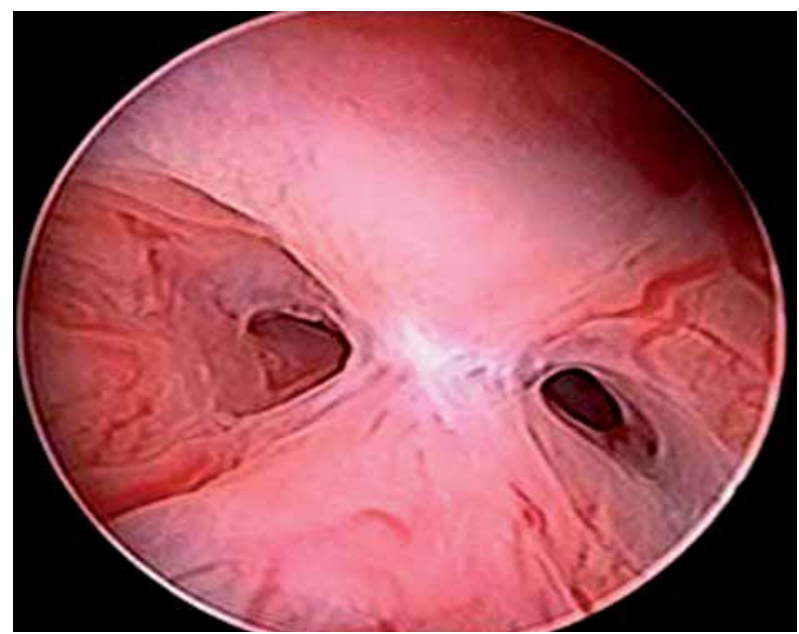

Figure 5. Hysteroscopic diagnosis of intra-uterine adhesions 
Table 1. Hysteroscopic and SIS findings in the studied population

\begin{tabular}{|c|c|c|}
\hline Variables & $\begin{array}{l}\text { Hysteroscopic findings } \\
\qquad(n=186)\end{array}$ & $\begin{array}{l}\text { SIS findings } \\
(n=186)\end{array}$ \\
\hline $\begin{array}{l}\text { Normal uterine cavity } \\
(n=111 \text { - true negative) }\end{array}$ & $\begin{array}{c}112(111+1) \\
\text { (1 case of sub-mucous fibroid was diagnosed as } \\
\text { normal cavity - false negative) }\end{array}$ & $\begin{array}{l}113(111+2) \\
(2 \text { cases were diagnosed as normal cavity } \\
=1 \text { cases of endometrial polyp }+1 \text { case of } \\
\text { Asherman's }=2 \text { cases false negative) }\end{array}$ \\
\hline $\begin{array}{l}\text { Abnormal uterine cavity } \\
(n=75-\text { true positive })\end{array}$ & $74(75-1)$ & $73(75-2)$ \\
\hline Endometrial polyp $(n=33)$ & 33 & 31 \\
\hline Sub-mucous fibroid ( $n=19$ ) & 18 & 19 \\
\hline Uterine septum $(n=9)$ & 9 & 9 \\
\hline $\begin{array}{l}\text { Intrauterine adhesions } \\
\text { (Asherman's) }(n=6)\end{array}$ & 6 & 5 \\
\hline $\begin{array}{l}\text { Endometrial hyperplasia } \\
\text { (thick endometrium) }(n=5)\end{array}$ & 5 & $\begin{array}{c}6 \text { (1 case of endometrial polyp was diagnosed as } \\
\text { endometrial hyperplasia }=\text { false positive) }\end{array}$ \\
\hline $\begin{array}{l}\text { Thin (atrophic) endometrium } \\
(n=3)\end{array}$ & 3 & 3 \\
\hline
\end{tabular}

The diagnoses of endometrial polyps, endometrial hyperplasia and thin (atrophic) endometrium were confirmed by the histopathological results, while the diagnosis of intrauterine adhesions and sub-mucous myoma was based on the hysteroscopic findings reviewed by senior gynaecologists. SIS - saline infusion hysterosonography.

Table 2. Sensitivity, specificity, accuracy and predictive values of hysteroscopy and SIS

\begin{tabular}{|c|c|c|c|}
\hline Variables & Hysteroscopy & SIS & $P$-value \\
\hline $\begin{array}{l}\text { Sensitivity }=\text { true positive/ } \\
\text { true positive }+ \text { false negative } \times 100\end{array}$ & $75 / 76(75+1) \times 100=98.7 \%$ & $75 / 77(50+2) \times 100=97.4 \%$ & $>0.05^{*}$ \\
\hline $\begin{array}{l}\text { Specificity }=\text { true negative/ } \\
\text { true negative }+ \text { false positive } \times 100\end{array}$ & $111 / 111(111+0) \times 100=100 \%$ & $111 / 112(111+1) \times 100=99.1 \%$ & $>0.05^{*}$ \\
\hline $\begin{array}{l}\text { PPV }=\text { true positive/ } \\
\text { (true positive }+ \text { false positive) } \times 100\end{array}$ & $75 / 75(75+0) \times 100=100 \%$ & $75 / 76(75+1) \times 100=98.7 \%$ & $>0.05^{*}$ \\
\hline $\begin{array}{l}\text { NPV }=\text { true negative/ } \\
\text { (true negative }+ \text { false negative) } \times 100\end{array}$ & $111 / 111(111+1) \times 100=99.1 \%$ & $111 / 113(111+2) \times 100=98.2 \%$ & $>0.05^{*}$ \\
\hline $\begin{array}{l}\text { Accuracy }=\text { true positive }+ \text { true } \\
\text { negative/(true positive }+ \text { true negative }+ \\
\text { false positive }+ \text { false negative) } \times 100\end{array}$ & $\begin{array}{c}75+111 /(75+111+0+1)= \\
186 / 187=99.5 \%\end{array}$ & $\begin{array}{c}75+111 /(75+111+1+2)= \\
186 / 189=94.4 \%\end{array}$ & $>0.05^{*}$ \\
\hline
\end{tabular}

In this study, hysteroscopy was more sensitive ( $98.7 \%$ vs. $97.4 \%)$, more specific ( $100 \%$ vs. $99.1 \%$ ), and more accurate (99.5\% vs. $98.4 \%)$ than SIS. In addition, hysteroscopy had higher predictive values, 100\% PPV and $99.1 \%$ NPV versus 98.7\% PPV and 98.2\% NPV for SIS in diagnosis of uterine cavity abnormalities in cases of abnormal uterine bleeding. However, these differences were not statistically significant $(p>0.05)$ using the chi-square $\left(\chi^{2}\right)$ test (Table 2$)$.

\section{Discussion}

Hysteroscopy is known as the gold standard procedure for uterine cavity assessment. It has been reported that the expansion of the uterine cavity with saline during trans-vaginal sonography improves the delineation of the uterine cavity and increases the detection of uterine cavity abnormalities [9-12].

One hundred and eighty-six women diagnosed with abnormal uterine bleeding were included in this compara- tive study, and agreed to have TVS assessment of the uterine cavity using saline (SIS) as the contrast medium beside the hysteroscopic assessment.

Uterine cavity abnormalities were diagnosed in $40.3 \%$ $(75 / 186)$ of the women included in this study $(17.7 \%$ $(33 / 186)$ endometrial polyps, $10.2 \%(19 / 186)$ sub-mucous fibroid, $4.8 \%$ (9/186) uterine septum, 3.2\% (6/186) uterine adhesions, $2.8 \%(5 / 186)$ endometrial hyperplasia, and $1.6 \%$ $(3 / 186)$ thin or atrophic endometrium).

Balić and Balić found that the most frequent abnormalities during evaluation of uterine cavities were endometrial polyps ( $60.7 \%$ by TVS and $35.7 \%$ by hysteroscopy), septate uterus (14.3\%), sub-mucosal myoma (12.5\%), endometrial hyperplasia ( $8.9 \%$ by TVS and $33.9 \%$ by hysteroscopy), and Asherman's syndrome (3.6\%) [13].

In addition, Kasius et al. screened 107 asymptomatic, infertile women for uterine cavity abnormalities before in-vitro fertilization/intra-cytoplasmic injection (IVF/ICSI), 
and they found that the most frequent abnormalities during evaluation of uterine cavities were endometrial polyps (11.2\%), septate uterus (1.9\%), and sub-mucosal myoma (1.9\%) [14].

During hysteroscopic evaluation of the uterine cavity of the studied cases, one case of small sub-mucous fibroid was diagnosed as normal uterine cavity (1 case false negative), while during SIS evaluation of the uterine cavity of the studied cases, 2 cases were diagnosed as normal uterine cavity (one cases of endometrial polyp + one case of Asherman's syndrome ( 2 cases false negative)), and one case of endometrial polyp was diagnosed as endometrial hyperplasia ( 1 case false positive).

In this study, hysteroscopy was more sensitive ( $98.7 \%$ vs. $97.4 \%$ ), more specific (100\% vs. $99.1 \%$ ), and more accurate (99.5\% vs. $98.4 \%)$ than SIS. In addition, hysteroscopy had higher predictive values, $100 \% \mathrm{PPV}$ and $99.1 \%$ NPV versus 98.7\% PPV and 98.2\% NPV for SIS in diagnosis of uterine cavity abnormalities. However, these differences were not statistically significant.

Balić and Balić concluded that the specificity of hysteroscopy in the diagnosis of endometrial polyp was $92.3 \%$ compared to $56.4 \%$ TVS, while the sensitivity was identical (100\%) [13]. Balić and Balić concluded that the sensitivity of TVS in the diagnosis of endometrial hyperplasia was $86.4 \%$ compared to $22.7 \%$ for hysteroscopy, while the specificity was identical (100\%) [13]. In addition, Balić and Balić concluded that hysteroscopy is more reliable in diagnosis of uterine cavity abnormalities than TVS and the use of a high frequency ultrasound probe leads to a lack of diagnostic clarity between endometrial polyps and hyperplasia [13].

Aydia et al. screened 44 patients by hysteroscopy, and SCHS (saline contrast hysteron-sonography) before IVF/ICSI. They diagnosed uterine cavity abnormalities in 16 women by hysteroscopy, and the SCHS was in complete agreement with hysteroscopy in 13 out of 16 cases [15]. In addition; Aydia et al. found that SCHS had a $87.5 \%$ sensitivity, 100\% specificity, 100\% PPV and 91.6\% NPV during evaluation of uterine cavity abnormalities, and they concluded that SCHS is a simple, well-tolerated procedure that can be performed to avoid expensive diagnostic hysteroscopy, and significant findings can be treated by operative hysteroscopy prior to IVF/ICSI [15].

Seshadri et al. concluded that SIS is commonly used for detailed evaluation of the uterine cavity as part of pre-treatment assessment in infertile women [16].

In addition, La Sala et al. concluded that TVS could be used as a first step investigation to exclude uterine pathologies, and could reduce the number of hysteroscopies performed in women with a normal uterine cavity [17].

Seshadri et al. in a recent systematic review concluded that SIS is a sensitive tool and comparable to the gold standard hysteroscopy in the diagnosis of uterine cavity abnormalities in infertile women [18].

Lost records during follow-up was the only limitation faced during this study, and a large comparative study is needed to confirm the diagnostic accuracy of SIS in diagnosis of uterine cavity abnormalities.
This study concluded that SIS is a simple, well-tolerated procedure can be used in an outpatient setting to diagnose uterine cavity anomalies in cases of abnormal uterine bleeding when outpatient hysteroscopy is not available.

\section{Conclusions}

Saline infusion sonography is a simple, well-tolerated procedure that can be used in an outpatient setting to diagnose uterine cavity anomalies in cases of abnormal uterine bleeding when outpatient hysteroscopy is not available or as a complementary tool to confirm the diagnosis detected by hysteroscopy.

\section{Conflict of interest}

The authors declare no conflict of interest.

\section{References}

1. Guner H, Tasdemir S, Tiras B. Comparison of diagnostic accuracy of saline infusion sonohysterography, transvaginal sonography and hysteroscopy. J Obstet Gynaecol 2011; 31: 54-8.

2. Abdelazim IA, Abdelrazak KM, Elbiaa AA, Al-Kadi M, Yehia AH. Accuracy of endometrial sampling compared to conventional dilatation and curettage in women with abnormal uterine bleeding. Arch Gynecol Obstet 2015; 291: 1121-6.

3. Abdelazim IA, Aboelezz A, Abdulkareem AF. Pipelle endometrial sampling versus conventional dilatation and curettage in patients with abnormal uterine bleeding. J Turk Ger Gynecol Assoc 2013; 14: 1-5.

4. Van Voorhis BJ. Ultrasound assessment of the uterus and fallopian tube in infertile women. Semin Reprod Med 2008; 26: 232-40.

5. Ibrahim A. Abdelazim IA, Abo Elezz A. Complementary roles of hysteroscopy and saline infusion hysterosonography in uterine cavity assessment before in vitro fertilization. Asian Pacific J Reprod 2012; 1: 13-6.

6. Bingol B, Gunenc Z, Gedikbasi A, Guner H, Tasdemir S, Tiras B. Comparison of diagnostic accuracy of saline infusion sonohysterography, transvaginal sonography and hysteroscopy. J Obstet Gynaecol 2011; 31: 54-8.

7. El-Sherbiny W, El-Mazny A, Abou-Salem N, Mostafa WS. The diagnostic accuracy of two- vs. three-dimensional sonohysterography for evaluation of the uterine cavity in the reproductive age. J Minim Invasive Gynecol 2015; 22: 127-31.

8. Gunes M, Erol O, Kayikcioglu F, Ozdegirmenci O, Secilmis O, Haberal A. Comparison of saline infusion sonography and histological findings in the evaluation of uterine cavity pathologies. Arch Gynecol Obstet 2008; 278: 513-6.

9. Hajishaiha M, Ghasemirad M, Karimpour N, Mladkova N, Boromand F. Transvaginal sonographic evaluation at different menstrual cycle phases in diagnosis of uterine lesions. Int J Womens Health 2011; 3: 353-7.

10. Pujar Y, Sherigar B, Patted S, Desai B, Dhumale H. Comparative evaluation of saline infusion sonohysterography and hysterolaparoscopy for diagnosis of uterine cavity abnormalities and tubal patency in infertility: a one year cross-sectional study. South Asian Fed Obstet Gynecol 2010; 2: 133-5.

11. Almog B, Shalom-Paz E, Shehata F, et al. Saline instillation sonohysterography test after normal baseline transvaginal sonography 
results in infertility patients. Is it justified? Gynecol Endocrinol 2011; 27: 286-9.

12. Carlos RC, Bree RL, Abrahamse PH, Fendrick AM. Cost effectiveness of saline-assisted hysterosonography and office hysteroscopy in the evaluation of postmenopausal bleeding. Acad Radiol 2001; 8: 835-44.

13. Balić $\mathrm{D}$, Balić A. Office hysteroscopy, transvaginal ultrasound and endometrial histology: a comparison in infertile patients. Acta Med Acad 2011; 40: 34-8.

14. Kasius JC, Broekmans FJ, Veersema S, et al. Observer agreement in the evaluation of the uterine cavity by hysteroscopy prior to in vitro fertilization. Hum Reprod 2011; 26: 801-7.

15. Ayida G, Chamberlain P, Barlow D, Kennedy S. Uterine cavity assessment prior to in vitro fertilization: comparison of transvaginal scanning, saline contrast hysterosonography and hysteroscopy. Ultrasound Obstet Gynecol 1997; 10: 59-62.

16. Seshadri S, Khalil M, Osman A, Clough A, Jayaprakasan K, Khalaf $\mathrm{Y}$. The evolving role of saline infusion sonography (SIS) in infertility. Eur J Obstet Gynecol Reprod Biol 2015; 185: 66-73.

17. La Sala GB, Blasi I, Gallinelli A, et al. Diagnostic accuracy of sonohysterography and transvaginal sonography as compared with hysteroscopy and endometrial biopsy: a prospective study. Minerva Ginecol 2011; 63: 421-7.

18. Seshadri S, El-Toukhy T, Douiri A, Jayaprakasan K, Khalaf Y. Diagnostic accuracy of saline infusion sonography in the evaluation of uterine cavity abnormalities prior to assisted reproductive techniques: a systematic review and meta-analyses. Hum Reprod Update 2015; 21: 262-74. 